\title{
Epigenetic deregulation of IGF2 and cervical cancer precursors in HIV+ and HIV- patients
}

\author{
Cathrine Hoyo ${ }^{1 *}$, Francine Overcash ${ }^{1}$, Zhiqing Huang ${ }^{2}$, Olola Oneko ${ }^{3}$, Brandi Vaquez ${ }^{4}$, Joseph Obure ${ }^{3}$, Pendo Mlay ${ }^{3}$, \\ John Bartlett ${ }^{5}$, Brenda Hernandez ${ }^{6}$, Susan K Murphy ${ }^{2}$ \\ From $12^{\text {th }}$ International Conference on Malignancies in AIDS and Other Acquired Immunodeficiencies \\ (ICMAOI) \\ Bethesda, MD, USA. 26-27 April, 2010
}

\section{Introduction}

Early detection and aggressive treatment programs to prevent cervical carcinoma in situ (CIS) and invasive uterine cervical cancer (ICC) have been available for more than 30 years with more than $80 \%$ population coverage. Despite this, 11,000 cases of ICC and 40,000 cases of CIS continue to be diagnosed in the United States annually. Women of African descent are at $>2$-fold higher risk of invasive cervical cancer death compared to other ethnic groups.

\section{Objective}

The overarching goal is to develop epigenetic biomarkers that can be used for early identification of aggressive cases likely to result in invasive cervical cancer and death.

\section{Methods}

We conducted a hospital-based, case-control study comprising 26 women with ICC, 18 with CIN2/3/HSIL and 41 with normal cytology, at Kilimanjaro Christian Medical Center in Moshi, Tanzania. We analyzed methylation of three regions in the IGF2/H19 imprinted domain known to regulate the expression of imprinted IGF2. Aberrant methylation is associated with IGF2 deregulation, including changes in expression, loss of imprinting, and neoplasia.

\section{Results}

At the IGF2/H19 imprint center upstream of $H 19$, methylation profiles for all women with no evidence of

\footnotetext{
*Correspondence: cathrine.hoyo@duke.edu

${ }^{1}$ Department of Community and Family Medicine, Duke University, Durham, NC, USA

Full list of author information is available at the end of the article
}

cervical abnormality or those with CIN2-CIN3 were within normal ranges (40\%-60\%), while $23 \%$ with invasive cancer had hypermethylation. In contrast, $25 \%$ of the CIN2/3 cases were abnormally hypomethylated at the IGF2 DMR in IGF2 intron 2, and the methylation profile worsened in the invasive cervical cancer cases with $64 \%$ having an abnormal methylation profile. A similar trend was found for the regulatory region in IGF2 intron 6 . Stratifying these analyses by HIV status in ICC revealed that aberrant intragenic IGF2 hypomethylation was observed only among women without HIV. These associations persisted after adjusting for HPV genotype.

\section{Conclusion}

Our findings suggest that regulation of IGF2 is substantially altered in CIN2 or worse via epigenetic alterations. DNA methylation profiles of these regions may be markers of risk of progression especially in HIV- women. The findings support our hypothesis that epigenetic deregulation of this imprinted gene could be useful in discriminating women with dysplasia likely to progress.

\section{Acknowledgements}

This article has been published as part of Infectious Agents and Cancer Volume 5 Supplement 1, 2010: Proceedings of the $12^{\text {th }}$ International Conference on Malignancies in AIDS and Other Acquired

Immunodeficiencies (ICMAOI). The full contents of the supplement are available online at http://www.biomedcentral.com/1750-9378/5? issue=S1.

\section{Author details}

'Department of Community and Family Medicine, Duke University, Durham, NC, USA. ${ }^{2}$ Department of Obstetrics and Gynecology, Duke University, Durham, NC, USA. ${ }^{3}$ Department of Obstetrics and Gynecology, Kilimanjaro Christian Medical Center, Moshi, Tanzania. ${ }^{4}$ Kilimanjaro Christian Medical Center-Duke Women's Health Collaboration, Moshi, Tanzania and Durham, 
NC, USA. ${ }^{5}$ Department of Medicine, Duke University, Durham, NC, USA.

${ }^{6}$ Cancer Research Center of Hawaii, University of Hawaii, Honolulu, HI, USA.

Published: 11 October 2010

doi:10.1186/1750-9378-5-S1-A27

Cite this article as: Hoyo et al:: Epigenetic deregulation of IGF2 and cervical cancer precursors in HIV+ and HIV- patients. Infectious Agents and Cancer 2010 5(Suppl 1):A27.

Submit your next manuscript to BioMed Central and take full advantage of:

- Convenient online submission

- Thorough peer review

- No space constraints or color figure charges

- Immediate publication on acceptance

- Inclusion in PubMed, CAS, Scopus and Google Scholar

- Research which is freely available for redistribution

Submit your manuscript at www.biomedcentral.com/submit

() BioMed Central 